\title{
Preparation of Candida albicans Biofilms for Transmission Electron Microscopy
}

\author{
Heather T. Taff ${ }^{\star}$ and David R. Andes ${ }^{\star}$
}

Department of Medicine, University of Wisconsin, Madison, USA

*For correspondence: htaff@wisc.edu; dra@medicine.wisc.edu

[Abstract] Transmission Electron Microscopy is a form of microscopy that allows for imaging of distinct portions of an individual cell. For Candida albicans biofilms, it is often used to visualize the cell walls of fixed samples of yeast and hyphae. This protocol describes how to grow, harvest, and fix Candida albicans biofilms in preparation for Transmission Electron Microscopy.

\section{Materials and Reagents}

1. Plate containing grown Candida albicans colonies

2. $500 \mathrm{ml} 0.22 \mu \mathrm{m}$ filter (Corning, catalog number: 431118)

3. Aluminum foil

4. Bacto-peptone (BD Biosciences, catalog number: 211677)

5. Bacto-yeast extract (BD Biosciences, catalog number: 212750)

6. Cell scraper (BD Biosciences, Falcon ${ }^{\circledR}$, catalog number: 353085)

7. Difco Dextrose (BD Biosciences, catalog number: 215530)

8. Glutaraldehyde (Sigma-Aldrich, catalog number: G5882)

9. Lead nitrate $\left(\mathrm{PbNO}_{3}\right)$ (Electron Microscopy Sciences, catalog number: 17900$)$

10. MOPS (Thermo Fisher Scientific, catalog number: BP308)

11. 4\% Osmium tetroxide (Electron Microscopy Sciences, catalog number: 19140)

12. Parafilm

13. Paraformaldehyde (Electron Microscopy Sciences, catalog number: 15710)

14. Propylene oxide (Electron Microscopy Sciences, catalog number: 20410)

15. RPMI 1640 (Sigma-Aldrich, catalog number: R6504)

16. Sodium cacodylate trihydrate (Sigma-Aldrich, catalog number: C0250)

17. Sodium chloride (Thermo Fisher Scientific, catalog number: S671-3)

18. Sodium citrate (Electron Microscopy Sciences, catalog number: $21140,500 \mathrm{gm}$ )

19. Sodium hydroxide (Sigma-Aldrich, catalog number: 59223C)

20. Sodium phosphate dibasic anhydrous (Thermo Fisher Scientific, catalog number: BP332500)

21. Sodium phosphate monobasic monohydrate (Thermo Fisher Scientific, catalog number: S369-500) 
22. Spurr's Resin Kit (Polyscience, catalog number: 01916-1)

23. Uridine (Sigma-Aldrich, catalog number: U3750)

24. Uranyl acetate (Electron Microscopy Sciences, catalog number: 22400)

25. YPD + uridine (see Recipes)

26. RPMI + MOPS (see Recipes)

27. 1x PBS (see Recipes)

28. Fixative (see Recipes)

29. Reynold's Lead Citrate Strain (see Recipes)

\section{Equipment}

1. $15 \mathrm{ml}$ conical tube (Corning, catalog number: CLS430055)

2. 6 well polystyrene plate (Grenier Bio-one, catalog number: 657160)

3. Hemocytometer

4. Shaking incubator with adjustable temperatures and speeds

5. Transmission Electron Microscope facility with trained microscopist

\section{Procedure}

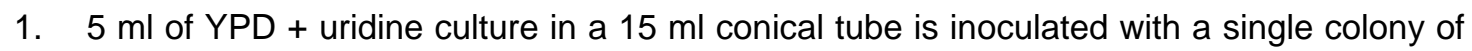
Candida albicans growing on a plate that is between 2 and 10 days old (age of colony may vary based on growth rate of particular strain). Most Candida strains and species should grow well in this medium, but if another medium is commonly used for a specific strain, that can be used instead.

2. Inoculum is incubated overnight at $30^{\circ} \mathrm{C}$ and $200 \mathrm{rpm}$.

3. Cell concentration of overnight culture is determined by cell counting on a hemocytometer.

4. Inoculum diluted to $1 \times 10^{6} \mathrm{cells} / \mathrm{ml}$ in RPMI + MOPS.

5. $1 \mathrm{ml}$ of diluted incolulum added to each well of a 6 well plate.

Note: Inoculum spread to cover the entire bottom of the well.

6. 6 well plate incubated at $30^{\circ} \mathrm{C}$ for $60 \mathrm{~min}$ without shaking.

7. Inoculum is then removed from each well gently, so as not to scratch away the newly forming biofilm.

8. $1 \mathrm{ml}$ of fresh RPMl + MOPS media is added gently to each well.

9. 6 well plates are wrapped in parafilm and aluminum foil and incubated for $24 \mathrm{~h}$ at $37^{\circ} \mathrm{C}$ and $50 \mathrm{rpm}$.

Note: It is very important that the biofilms not be shaken above $50 \mathrm{rpm}$, as this will dislodge the growing biofilm from the plate bottom. 
10. After $24 \mathrm{~h}$, media is gently removed so as not to disturb the biofilm and replaced with $1 \mathrm{ml}$ of fresh RPMI + MOPS.

Note: Tilting the 6 well plates and gently placing your pipet tip in the corner of the well helps to prevent too much disruption of the fragile biofilm.

11. 6 well plates are re-wrapped as before and incubated another $24 \mathrm{~h}$ at $37^{\circ} \mathrm{C}$ and $50 \mathrm{rpm}$.

12. After the second $24 \mathrm{~h}$ incubation, the media is removed from the wells and the biofilms are gently washed $1 \mathrm{x}$ in $1 \mathrm{ml}$ of $1 x$ PBS. It is important to slowly pipet in the PBS so as not to disturb the delicate biofilms. The PBS wash can be removed immediately after adding it to the biofilm.

13. Harvest each biofilm in $2 \mathrm{ml}$ of $1 \times$ PBS and store in a $15 \mathrm{ml}$ conical tube.

Note: Harvesting is best done by adding $1 \mathrm{ml}$ of PBS into the well and scraping away the biofilm with a plastic spatula, and adding the biofilm to the conical tube. Then repeat this process with the second $1 \mathrm{ml}$ of PBS to collect any remnants.

14. Conical tubes are gently centrifuged at $720 \times g$ for 5 min at room temperature.

15. Supernatant is discarded and the pellet is resuspended in $2 \mathrm{ml}$ of Fixative.

16. Tubes can be stored at $4{ }^{\circ} \mathrm{C}$ until ready for imaging by a trained transmission electron microscopist. It is recommended that the tubes not be stored more than a few days.

17. The following steps are a summary of those performed by a trained transmission electron microscopist.

a. Cells are postfixed in $1 \%$ osmium tetroxide.

b. Samples are then dehydrated by soaking for 10 min each in increasing concentrations of ethanol $(30 \%, 50 \%, 70 \%, 85 \%, 90 \%, 95 \%$, and $100 \%)$.

c. Next, samples are rinsed $3 \times 10 \mathrm{~min}$ in $100 \%$ propylene oxide then embedded in Spurr's resin.

d. $\quad 70 \mathrm{~nm}$ sections are cut and placed on copper grids and poststained for 5 min with $8 \%$ uranyl acetate in $50 \%$ ethanol and for 5 min in Reynold's lead citrate stain.

e. Samples can now be analyzed by TEM. A sample picture of a reference strain Candida albicans biofilm is shown below (Figure 1). Most pictures will only show one or two cells at a time, and usually cross-sectioned so that you can see inside the cells. Scale bar represents $1 \mu \mathrm{m}$. 


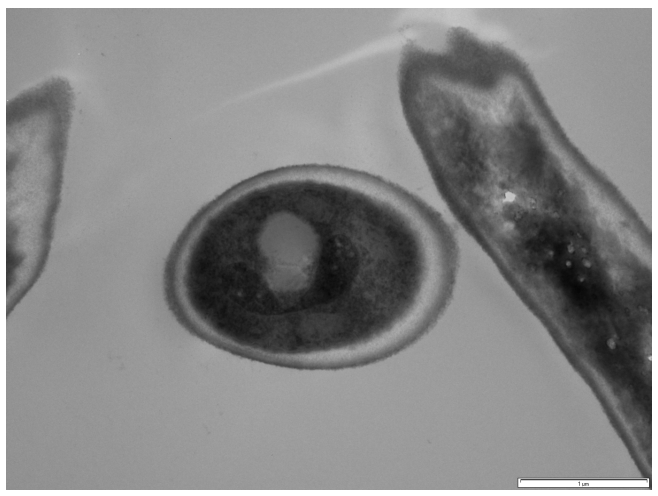

Figure 1. Transmission Electron Microscopy image of a Candida albicans biofilm cell

\section{$\underline{\text { Recipes }}$}

1. $\mathrm{YPD}+$ uridine

$\begin{array}{ll}\text { Bacto-yeast extract (1\%) } & 10 \mathrm{~g} \\ \text { Bacto-peptone (2\%) } & 20 \mathrm{~g} \\ \text { Dextrose (2\%) } & 20 \mathrm{~g} \\ \text { Uridine } & 0.08 \mathrm{~g} \\ \text { Distilled water } & 1,000 \mathrm{ml}\end{array}$

Combine all ingredients and aliquot into $100 \mathrm{ml}$ bottles. Autoclave bottles on liquid cycle to sterilize.

2. $\mathrm{RPMI}+\mathrm{MOPS}$

$\begin{array}{ll}\text { RPMI } 1640 & 10.4 \mathrm{~g} \\ \text { MOPS } & 34.5 \mathrm{~g} \\ \text { Distilled water } & 700 \mathrm{ml}\end{array}$

Combine all ingredients in a $2 \mathrm{~L}$ flask. Use a $10 \mathrm{ml}$ pipette to adjust $\mathrm{pH}$ to 7.0 using Sodium hydroxide $(5 \mathrm{~N})$. Bring volume up to $1 \mathrm{~L}$ with distilled water. Filter sterilize RPMI + MOPS into $500 \mathrm{ml}$ bottles. Use at $37{ }^{\circ} \mathrm{C}$, but can store for up to 6 months at $4{ }^{\circ} \mathrm{C}$ to prevent contaminant growth.

3. $1 \times$ PBS

Sodium phosphate monobasic monohydrate $(\mathrm{mw}=137.99 ; 0.038 \mathrm{M}) \quad 2.62 \mathrm{~g}$

Sodium phosphate dibasic anhydrous $11.5 \mathrm{~g}$

Sodium chloride $43.84 \mathrm{~g}$

Distilled water $500 \mathrm{ml}$

Add above ingredients to $450 \mathrm{ml}$ distilled water. Adjust $\mathrm{pH}$ to 7.4 by adding $1 \mathrm{M} \mathrm{NaOH}$ if necessary. Bring final volume to $500 \mathrm{ml}$ distilled water. This makes 10x PBS stock. Dilute in distilled water 1:10 for final concentration of PBS. 
4. Fixative

$2.5 \%$ glutaraldehyde

2.0\% paraformaldehyde

Add above ingredients to $0.1 \mathrm{M}$ sodium cacodylate trihydrate. Use caution with this reagent, as it is very toxic.

5. Reynold's lead citrate stain

Lead nitrate

Sodium citrate

$1.76 \mathrm{~g}$

Distilled water

$30 \mathrm{ml}$

$1 \mathrm{~N}$ Sodium hydroxide

$8 \mathrm{ml}$

Place all ingredients in a $50 \mathrm{ml}$ flask and shake forcefully for $1 \mathrm{~min}$, then intermittently for 30 min until fully dissolved. Then add $8 \mathrm{ml}$ of $\mathrm{NaOH}$ and bring volume up to $50 \mathrm{ml}$ with distilled water. Filter sterilize before using.

\section{References}

1. Bowling Green State University (2012). Reynold's Lead Citrate Stain. Retrieved from www.bgsu.edu/departments/biology/facilities/MnM/TEM/ReynoldsLeadStain.pdf.

2. Nett, J. E., Sanchez, H., Cain, M. T., Ross, K. M. and Andes, D. R. (2011). Interface of Candida albicans biofilm matrix-associated drug resistance and cell wall integrity regulation. Eukaryot Cell 10(12): 1660-1669.

3. Nett, J., Lincoln, L., Marchillo, K., Massey, R., Holoyda, K., Hoff, B., VanHandel, M. and Andes, D. (2007). Putative role of beta-1,3 glucans in Candida albicans biofilm resistance. Antimicrob Agents Chemother 51(2): 510-520.

4. Taff, H. T., Nett, J. E., Zarnowski, R., Ross, K. M., Sanchez, H., Cain, M. T., Hamaker, J., Mitchell, A. P. and Andes, D. R. (2012). A Candida biofilm-induced pathway for matrix glucan delivery: implications for drug resistance. PLoS Pathog 8(8): e1002848. 